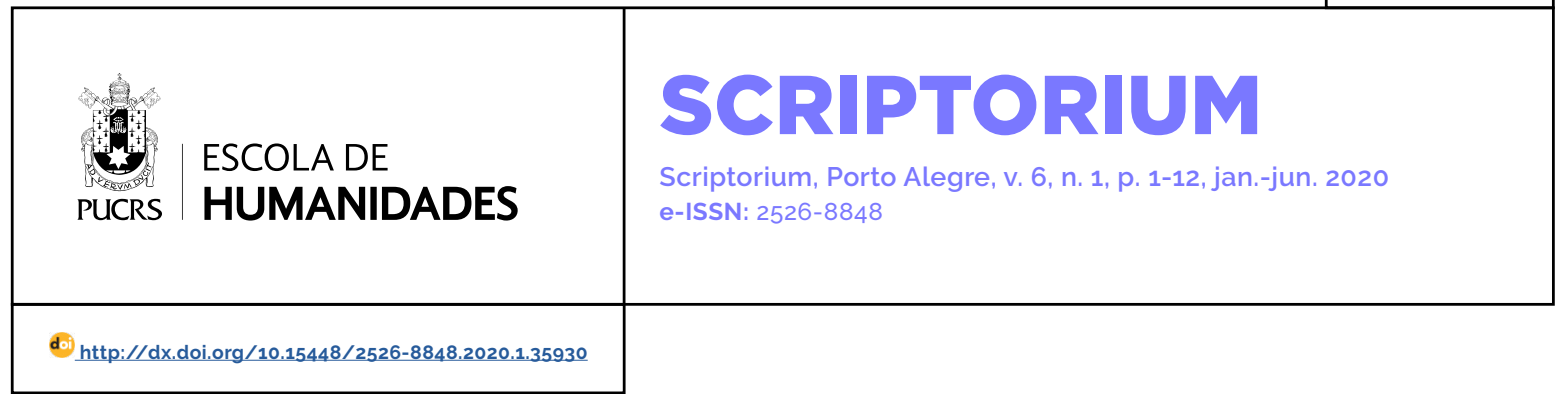

TEMATHIS

\title{
A importância da música na construção da atmosfera e do efeito em uma narrativa de terror
}

On the importance of music in constructing atmosphere and effect in horror stories

\section{Gustavo Melo Czekster ${ }^{1}$ orcid.org/0000-0003-3952-0495 gusczekster@gmail.com}

Recebido em: 09 out. 2019 Aceito em: 26 jan. 2020 Publicado em: 20 jul. 2020.
Resumo: Por meio das ideias de Edgar Allan Poe a respeito das formas de criação de um efeito no leitor e com base nas lições de H. P. Lovecraft sobre a atmosfera das narrativas sobrenaturais, o presente artigo se propõe a discutir como a música pode ser um fator decisivo na construção de uma obra literária do gênero terror. Para tanto, o artigo analisa a forma com que as músicas são elementos importantes para o desenvolvimento da tensão narrativa em contos de H. P. Lovecraft, Nathaniel Hawthorne e Stephen King, detalhando as estratégias narrativas adotadas por cada um para destacar uma música imaginada pelo leitor como parte integrante da atmosfera de uma história de terror.

Palavras-chave: Escrita Criativa. Narrativas de terror. Efeito. Atmosfera.

Abstract: Through the theories of Edgar Allan Poe regarding the ways of impressing a vivid effect on the reader and based on the teachings of H. P. Lovecraft about atmosphere in stories of the supernatural, this article aims to analyze how music may be a decisive factor in constructing a literary work of horror genre. Therefore, this article analyzes the ways in which music is an important element to the setting of narrative tension in H. P. Lovecraft, Nathaniel Hawthorne and Stephen King, providing details on writing strategies adopted by each author to highlight an imagined song as an essential part of a horror story atmosphere.

Keywords: Creative Writing. Horror Stories. Effect. Atmosphere.

\section{Introdução}

Quando se trata de uma narrativa cinematográfica de terror, é comum a análise do quanto à música de determinado filme foi fundamental para a construção do clima desejado, transmitindo o terror e o suspense como um auxilio sonoro para aquilo que será revelado aos olhos do espectador. Nesse sentido, após explicar o uso de stingers, crescendos e glissandos nos filmes de terror, Rodrigo Carreiro afirma que a utilização da música neste gênero cinematográfico decorre de uma razão estilística, qual seja, "o uso constante de dissonâncias para demarcar uma atmosfera de desequilibrio, incompletude, instabilidade e estranheza" (CARREIRO, 2011, p. 49).

Percebe-se, assim, que a música possui uma finalidade não só estética dentro de uma narrativa cinematográfica de terror, mas também tem por objetivo consolidar a atmosfera de medo, gerando uma impressão mais durável nos espectadores por mexer com suas emoções no aspecto mais primitivo. ${ }^{2}$ Ela não é uma coincidência, mas surge na obra com uma função prática. 
Ainda que a sua utilização no cinema de terror seja algo essencial para a construção do clima desejado pelo cineasta não existem estudos suficientes abordando a relação entre a literatura e a música na esfera da construção de um determinado efeito no interior da obra literária, em especial as desse gênero. Entretanto, há um reconhecimento por parte dos profissionais da área, o que fez inclusive, Alfred Hitchcock a dedicar o prêmio que ganhou no American Film Institut (AFI) aos responsáveis pelas trilhas sonoras dos seus filmes, por estimular o próprio ator a entrar na cena e fazer com que as pessoas acreditem no que estão vendo (ALVES; MATOS, 2010, p. 18).

Tal compreensão seria muito importante em termos de criação literária, eis que a música, assim como ocorre com o cinema, pode ajudar o leitor a entrar no clima da história, atuando na "willing suspension of disbelief for the moment, which constitutes poetic faith" mencionada por Samuel Taylor Coleridge (COMPAGNON, 1999, p. 98). Por conseguinte, através da utilização dos mecanismos teóricos característicos da Escrita Criativa, pretende-se investigar as maneiras através das quais um escritor pode utilizar a música na sua obra literária com o escopo de criar tensão e auxiliar na necessária elaboração da atmosfera de uma história de terror.

\section{Literatura e Música: uma relação de mútuo fascínio}

Engana-se quem pensa que as artes são passíveis de uma separação estanque, em que cada uma vive dentro do seu próprio microcosmo de atuação, ou seja, a música lida com as capacidades derivadas do som, à literatura pertence o domínio da palavra e a pintura trata da representação pictórica de coisas ou pessoas, para ficarmos em alguns exemplos. As artes encontram-se em constante diálogo, diluindo as fronteiras ao ponto de considerarmos que a obra funciona, de forma mais plena, quando conjuga diferentes elementos artísticos no seu interior, impedindo-a de ser somente um anteparo material para se constituir em um objeto estético por influência de um espectador. Na feliz analogia de Flávio R. Kothe, "a obra é o local do desencontro de duas solidões", uma vez que:

\begin{abstract}
Aparentando falar só consigo mesmo e com o seu objeto durante o processo criativo, o autor ao produzir o seu artefato se volta sem cessar para o seu receptor virtual, para o outro de si mesmo. E o leitor, ao projetar-se no texto, está se abrindo para a fala do outro. Cada um é capaz de se encontrar não com o outro, mas com a fala do outro, com a sombra do outro, sombra que ele já tem virtualmente em si mesmo pois não é mais auto-idêntico a partir do momento em que se põe a ler, mergulhado que está na alteridade do outro que mergulha nele (KOTHE, 1981, p. 25).
\end{abstract}

Por meio da capacidade da obra de arte de se referir não somente ao seu campo de atuação, mas por dialogar com outras formas artísticas no interior da sua estrutura, é possivel constatar que, tanto uma peça musical pode crescer em intensidade e emoção quando se cerca de uma obra literária, quanto o contrário também é passivel de ocorrer. Ou seja, uma obra literária se fortalecer por meio da associação feita pelo leitor com uma música.

A guisa de exemplo vale lembrar que a Sinfonia n. og de Ludwig van Beethoven baseia-se no poema "Ode à alegria", de Friedrich Schiller. Sendo que, como Richard Wagner bem destaca, para ajeitar a musicalidade do poema que the serviu de inspiração, Beethoven acabou modificando dois versos, os quais depois vieram a se tornar parte do poema original (WAGNER, 2010, p. 94-96).

Graças ao avanço tecnológico, essa associação se torna cada vez mais comum nos tempos atuais: algumas obras da literatura contemporânea são lançadas no mercado com playlists associadas, em especial através de sistemas de compartilhamento de mídia, tais como o Spotify, YouTube, Google Music, entre outros. ${ }^{3}$ Ainda que nenhum estudo tenha sido realizado sobre o assunto, acredito que essas criações tem função dupla: ao mesmo tempo em

Entre as inúmeras obras literárias cujos autores criaram playlists para os leitores, a título de exemplo destaco a playlist elaborada por Cesar Alcázar para o livro "A culpa é da noite" (AVEC, 2019), disponivel em https://www.youtube.com/playlist?list=PLLsjKXLJnt-3BGRjsG1HEM7D3UaYAch8J, e a playlist desenvolvida por Bibiana Barros Simionatto para o livro "Lauren" (Caos \& Letras, 2019), disponível em https://www.youtube.com/playlist?list=PLOAogEsPhJ4tMDKgCfKRUuoT4gfJKXz1J. 
que permite ao leitor saber qual é a música usada como inspiração para o autor desenvolver o seu livro, auxilia também a imaginar qual seria a trilha sonora de certa personagem ou cena, trazendo um elemento da realidade externa à obra (no caso, uma música) para dentro da trama. É como se o escritor, além de responsável pela evolução da trama, também dirigisse as sensações de quem lê sua obra por meio da trilha sonora que escolheu para o seu próprio livro.

Conforme demonstra o exemplo das playlists como suporte material na construção de uma obra literária, a relação entre literatura e música sempre foi próxima. Tal fato é mais facilmente verificável na poesia, forma literária que busca o ritmo através da máxima potência da palavra.

Não é raro que muitas músicas atribuam sonoridades para poemas originalmente escritos, não musicados, ou que alguns poemas - a título de elogio - tenham o seu ritmo comparado ao de uma música. Ezra Pound traça com nitidez a distinção entre poesia e música ao afirmar que "não é imprescindivel que um poema se baseie na musicalidade, mas caso isso aconteça, tal música deve ser capaz de deleitar o especialista" (POUND, 1976, p. 12).

Mais recentemente, a íntima relação entre poesia e música foi alvo de debates intensos na mídia após a atribuição do Prêmio Nobel de Literatura de 2016 ao cantor folk Bob Dylan. Muitos questionamentos foram realizados, ainda mais quando se considerou que a obra do cantor era uma poesia, apesar de estar em forma de música e não em no interior de um livro. A própria justificativa dada pela Academia Sueca considera a música vocal como um gênero da poesia: "Bob Dylan, for having created new poetic expressions within the great American song tradition" (MLA, 2016).

Existe uma série de imprecisões teóricas ao atribuir o caráter de poesia a uma música vocal, as quais podem ser resumidas na seguinte dúvida: se somente as músicas com versos são poesias, as outras são o quê? Para esclarecer tais dúvidas, melhor pensar como Jorge Luis Borges que, após tecer considerações sobre o tema como arte autônoma, e que todas as artes desejam ser como ela, pois, na música, "forma e substância não podem ser cindidas uma da outra", acaba afirmando:

No caso da literatura, e especialmente da po-
esia, o caso parece ser exatamente o oposto.
Podemos contar o enredo de A Letra Escarlate
a um amigo nosso que não a leu, e suponho
que possamos até relatar o modelo, a moldura,
o enredo, digamos, do soneto "Leda e o cisne"
de Yeats. De modo que acabamos tomando a
poesia como uma arte bastarda, como sendo
algo hibrido (BORGES, 2000, p. 83).

Imaginar a poesia como algo híbrido, que permite ou não a conversão para uma forma musical, também auxilia na ideia de que buscar uma equiparação entre literatura e música, apesar do mútuo fascínio com que ambas tentam se aproximar, é acabar diminuindo a força das duas, eis que pressupõe uma relação de forças inexistente na prática. Partindo da premissa de que os estudos investigatórios da relação entre literatura e música partem de uma equiparação impossivel entre os dois sistemas, os quais são transmitidos através de meios diferentes, Steven Paul Scher (2004) afirma que deveriam ser estudadas duas abordagens diferentes: a primeira seria "literature in music", ou seja, como a literatura aparece na forma musical, seja através de inspiração, seja através de adaptação ou mesmo transcriação dentro dela, e a segunda seria a music in literature:

'Music in literature' is the only one of the three areas of the inter-relation that encompasses exclusively literary works of art. While unalterably bound to the literary medium of expression, in one way or another all these works represent attempts at 'musicalization' of literature or verbalization of music. No matter how similar to music purely verbal constructs may be, in the nature oh their material they remain fundamentally different from works whose medium is primarily musical, such as absolute, vocal, or program music. Literary texts cannot transcend the confines of literary texture and become musical texture. Literature lacks the unique acoustic quality of music: only through ingenious linguistic means or specialliterary techniques can it imply, evoke. imitate, or otherwise indirectly approximate actual music and thus create what amounts at best to a verbal semblance of music. Firmly anchored in tle literary realm, manifestations of music in literature promise to be rewarding for literary study. But the possibilities of literary treatment of music are so numerous and diverse that only the three basic kinds can be discussed and illustrated here in some detail: 'word music', musical structures and techniques in literary works and 'verbal music'. They will be 
reviewed as part of a larger framework of the major methodological strategies practiced by critics who deal with music-literary parallels: the synchronic approach concerning the systematic relations and the diachronic approach concerning the historical relations between the two arts (SCHER, 2004, p. 179-180).

Da mesma forma que inúmeras músicas tiveram obras literárias como ponto de partida, existem livros que as utilizaram como forma de inspiração. A prova está nos diversos exemplos seja como tentativa de livre interpretação literária para canções existentes, como é o caso de "Cobain" (2016), coletânea de contos organizada por Sérgio Tavares em homenagem ao álbum Nevermind, da banda americana Nirvana; seja tratando de músicas imaginárias que não existem no mundo real, somente na ficção, como ocorre em "Contos para ler ouvindo música" (2005), conjunto de narrativas de vários autores, todas contendo referências musicais, organizada por Miguel Sanches Neto; seja como suporte material em torno do qual a trama se desenvolve - podemos citar como exemplo "Ribamar" (2013), de José Castello, em que os capítulos do livro são trechos em notação musical de uma cantiga entoada na infância do narrador; seja ainda como artifício para envolver o leitor e desencadear as memórias do protagonista, caso de "Instrumental: memórias de música, medicação e loucura" (2017), de James Rhodes, cuja trama é construida em torno de músicas lembradas pelos narrador e que se ligam a momentos-chave da sua vida.

Existem várias formas de estudarmos a música na literatura, como sugere Steven Paul Scher (2004). E, uma delas, é a maneira através da qual a música ajuda a construir a atmosfera de uma história de terror. Para isso, propicia um efeito nos leitores, algo que, à luz da Escrita Criativa, pode auxiliar na análise das estratégias ficcionais adotadas por um autor no interior da narrativa, especialmente no gênero terror.

\section{Efeito e a Atmosfera nas Narrativas de Terror}

Uma questão essencial para qualquer narrativa de terror é a construção de um efeito para o seu leitor, algo que lhe permita entrar na história de tal maneira que, utilizando somente palavras, o autor seja capaz de lhe transmitir medo, angústia, desespero. Boa parte do seu sucesso se concentra na eficácia ou não na transmissão do efeito para o público, algo que Edgar Alan Poe, no essencial ensaio "A filosofia da composição", já abordava:

Eu prefiro começar com a consideração de um efeito. Mantendo sempre a originalidade em vista, pois é falso a si mesmo quem se arrisca a dispensar uma fonte de interesse tão evidente e tão facilmente alcançável, digo-me, em primeiro lugar: "Dentre os inúmeros efeitos, ou impressões a que são suscetiveis o coração, a inteligência ou, mais geralmente, a alma, qual irei eu, na ocasião atual, escolher?" (POE, 1999, p.101-102).

O efeito é algo refletido de antemão pelo autor, com vistas a causar um resultado na imaginação do leitor. E é por esse motivo que Poe afirma que, depois de saber o que deseja, a sua dúvida se torna como chegar de maneira mais eficaz ao resultado pretendido, se vai ser através dos acontecimentos narrados ou se vai ser por intermédio do tom adotado pela prosa (POE, 1999, p. 102).

Ainda que seja um ensaio que parte da visão de literatura do próprio autor, e que existam uma série de outros componentes que afetam a verossimilhança da obra além do propósito, não seria exagero afirmar que, para Edgar Allan Poe, em narrativas de terror, um eventual problema narrativo ocorre em um dos vértices do seguinte triângulo: o autor não sabia qual efeito desejava causar; ele narrou o acontecimento de forma que este se dissociou do efeito pretendido ou adotou um tom errado diante da narrativa pretendida (contou uma história trágica com um tom cômico, por exemplo).

No entanto, não basta desejar um efeito e buscar inseri-lo na narrativa que está feito o trabalho mais importante da escrita: também é necessário acalentar esse propósito, destacá-lo, cercá-lo de todas as condições para que apareça de forma vibrante em meio à narrativa. Nesse aspecto, para ele restar ainda mais singular e forte no contexto de uma narrativa de terror, precisa estar acompanhado da atmosfera adequada.

O autor que melhor abordou a questão da atmosfera no interior de uma narrativa de terror foi 
Howard Phillip Lovecraft. Atento leitor de Edgar Allan Poe, Lovecraft escreveu um ensaio decisivo para os estudos da literatura fantástica, o qual denominou "O horror sobrenatural em literatura", em que afirmou:

Atmosfera é a coisa mais importante, pois o critério final de autenticidade não é a harmonização de um enredo, mas a criação de uma determinada sensação. Podemos dizer, generalizando, que uma história fantástica cuja intenção seja ensinar ou produzir um efeito social, ou uma em que os horrores são explicados no final por meios naturais, não é uma genuina história de medo cósmico; mas persiste o fato de que essas narrativas muitas vezes possuem, em seções isoladas, toques atmosféricos que preenchem todas as condições da verdadeira literatura de horror sobrenatural. Portanto, devemos julgar uma história fantástica não pela intenção do autor ou pela simples mecânica do enredo, mas pelo nivel emocional que ela atinge em seu ponto menos banal (LOVECRAFT, 2007, p. 17).

Para o escritor norte-americano, a simples intenção do autor de criar um efeito não basta para determinar o êxito de uma história fantástica ou de terror sobrenatural. Outros elementos se fazem necessários para que esta narrativa tenha a força desejada, tais como o uso de cenários, a elaboração de cenas de alta tensão dramática, o desenvolvimento psíquico do personagem, a distância que o narrador apresenta em relação à história contada, entre outras características. Isso leva Lovecratf a considerar que o importante em uma história de terror sobrenatural é se a atmosfera engendrada pelo autor é capaz de deixar o leitor com um profundo sentimento de pavor ou o faz questionar as potências e esferas desconhecidas do Universo (LOVECRAFT, 2007, p. 18).

A leitura, assim como qualquer ato humano, envolve uma série de emoções individuais, que acabam se conectando à narrativa, aproximando - ou afastando - o leitor da trama. Isso explica o fato de determinado tipo de público gostar de uma personagem e outro tipo acabar por repudiá-lo, pois cada um interage de maneira diferente com a trama disposta em um livro.

Nesse aspecto, seria válido perguntarmos se o leitor realmente sente essas reações ou se acredita que está tendo tais sentimentos, ou seja, é induzido a sentir algo por meio dos mecanismos ficcionais que norteiam a trama. Por esse motivo, Gregory Currie (1993), em vasto estudo sobre a natureza da ficção, acaba distinguindo entre o "believe" (acreditar) e o "make-believe" (fazer acreditar), dizendo que o leitor acredita sentir algo, mas é o escritor quem o faz acreditar nesse sentimento, ou seja, todas as emoções advindas de um livro resultam de uma interpretação do escritor em relação à alma humana, induzindo quem o lê a acreditar em algo similar às suas experiências pessoais:

\begin{abstract}
To read a work of fiction is to engage in a largely internalized game of make-believe. The reader makes believe that he is reading an account of known fact, and adopts an attitude of make-believe toward the propositions of the story. $\mathrm{He}$ does not believe the story, he makes believe it. The difference between fiction reading and nonfiction reading is that, with the former, make-belief takes over the role that otherwise would be occupied by belief. And this suggests the following hypothesis: our responses to fiction differ from emotions in that make-belief is substituted for belief (CURRIE, 1993, p. 196).
\end{abstract}

Pensar nos termos do que trata Currie ajuda a justificar a importância que a atmosfera possui para ajudar a criar o efeito desejado no leitor. Não basta fazer acreditar que está sentindo algo, é preciso estar completamente envolvido pela atmosfera da história para se sentir como parte indissolúvel dela.

No momento em que o autor de uma narrativa de terror decide fazer com que o leitor sinta a trama como se fosse algo real, não busca fomentar a antipatia ou a simpatia por uma determinada personagem ou por um acontecimento, mas sim suscitar medo, que é outra espécie de emoção. O leitor de uma narrativa de terror precisa acreditar que o medo não está confinado ao ambiente do livro, mas que a atmosfera saiu do seu interior e tomou conta do espaço em que ele está, o que justifica o fato de uma boa história de terror deixar seu público com medo de dormir no escuro, com pesadelos ou com receios dos sons normais do cotidiano, que passam a ser vistos sob uma nova ótica após a leitura.

Por este motivo, quando tratamos dos conceitos de efeito e de atmosfera em uma narrativa de terror, entendemos que os dois são essenciais para a efetividade da ficção urdida pelo autor. Ao mesmo tempo em que o efeito projeta a intenção daquilo que ele deseja causar, a atmosfera ajuda 
a consolidar tal sensação por meio de estratégias narrativas que intensificam ou mantém o efeito sempre à espreita, sempre sendo lembrado pelo leitor. Em tal contexto, importante observar com a música pode ser usada como um elemento de tensão nas narrativas de terror.

\section{A Música nas Narrativas de Terror}

A música e o terror costumam caminhar juntos. No passado, músicas que evocavam a morte ou a loucura acabaram se transformando em sucessos, e composições de Camille Saint-Saëns ("Danse macabre") e Franz Liszt ("La lugubre gondola", "Pensée des morts" e "Funérailles") se tornaram partes importantes da história da música (BURROWS, 2010).

Também não se pode deixar de lado a noção de que a música causa, necessariamente, um efeito no ouvinte e, não raro, esse impacto pode estar associado a uma determinada atmosfera. A título de exemplo, podemos listar os cantos gregorianos, cuja tonalidade vocal grave, em geral entoado em ambientes soturnos ou introspectivos como capelas, monastérios ou igrejas, acabam induzindo um efeito de meditação e calma (CARPEAUX, 2005, p. 34-36).

Por causa dessa noção, de que a música desperta sentimentos e emoções - algo consubstanciado no mito de Orfeu, cuja lira era capaz de apaziguar as feras e instaurar sentimentos entre aqueles que o escutavam -, no periodo barroco, desenvolveu-se a Doutrina dos Afetos. Esta era uma revisão do conceito falado por Aristóteles em "Política", quando afirma que a música deveria ser ensinada aos jovens, pois possui a capacidade de auxiliar no lazer e no prazer, além de criar estados de espírito favoráveis no momento em que mexe com emoções e sentimentos (ARISTÓTELES, 2006, p. 78-81).

Também não se pode deixar de mencionar a Doutrina dos Afetos, que atingiu o seu apogeu com René Descartes, responsável por "Compendium Musicae" (1638) e "As paixões da alma" (1649). Neste caso, ele afirma que o intérprete da música e o seu público devem estar imbuídos da mesma emoção, a qual seria transmissivel por intermédio da performance artística (CASTRO, 2005, p. 17-18).
Boa parte das ideias atuais da relação que a música estabelece com seus ouvintes parte da Doutrina dos Afetos, considerando que ela pretende causar uma emoção em quem a escuta e, por seu intermédio, gerar-lhe uma espécie de catarse, algo que faça a pessoa se sentir aliviada, motivada, contente. A ideia de uma música que não envolva o seu ouvinte é descartada pelo mesmo motivo que um leitor afasta um livro desinteressante: é aborrecida (JOURDAIN, 1998, p. 402).

Poderíamos discutir se a música moderna, em especial aquela produzida após a Segunda Guerra Mundial, não qual existe uma busca pela atonalidade, pelo desconforto do ouvinte e pela quebra ritmica, ainda busca suscitar emoções nobres (CARPEAUX, 2005, p. 414-479). Entretanto, é impossivel ignorar que ela está ligada à emoção, e a nossa visão tradicional vincula a música à vontade de nos sentirmos seres humanos melhores:

Como vimos, a maioria das composições care-
ce de uma referência especifica, que combine
com os conteúdos do mundo. Mas, quando le-
vamos para a música nossas próprias situações
de vida, podemos fazer dela o que quisermos.
A música idealiza tanto as emoções negativas
quanto as positivas. Com isso, ela aperfeiçoa
momentaneamente nossas vidas emocionais
individuais. O "significado" que sentimos não
está na música como tal, mas em nossas pró-
prias reações ao mundo, reações que carre-
gamos sempre conosco. A música serve para
aperfeiçoar essas reações, para torná-las belas.
Assim fazendo, a música confere dignidade a
experiências que, com frequência, estão lon-
ge de serem dignas. E, conferindo prazer até
mesmo a emoções negativas, a música serve
para justificar sofrimentos grandes e pequenos,
garantindo-nos que tudo não foi a troco de
nada (JOURDAIN, 1998, p. 405).

Ainda que esteja ligada à ideia de trazer uma sensação boa para o ouvinte, na literatura de terror, ela pode ser usada como um elemento narrativo que transmite terror, tensão e medo, tudo para atender à necessidade de criar uma atmosfera em torno do efeito desejado. É menos uma sonoridade e mais uma estratégia ficcional utilizada pelo autor para auxiliá-lo na construção do efeito e, nesse sentido, é mais um artifício de linguagem do que um som imbuido de sentido. No entanto, por ser produzida dentro de um tempo em específico, e por se relacionar tanto com o 
tempo da narrativa quanto o tempo cronológico do leitor e o tempo de leitura, também poderia ser considerada como uma questão temporal da narrativa (CZEKSTER, 2016).

Também é importante destacar que a presença da música na literatura pode acontecer de várias formas, embora o objeto de análise nesse trabalho ser somente verificar a música como efeito e elemento constitutivo da atmosfera das narrativas de terror. Nenhum elemento estético surge desprovido de origem, e a música pode aparecer como parte formadora da experiência literária simultânea - quando é descrita ou estabelece algum diálogo com a obra - ou posterior a ela - quando serve como inspiração. Stephen King, por exemplo, admite sempre escrever sob a influência dela, pois "a música me envolve e mantém o mundo lá fora" (KING, 2015, p. 135-136). Nesse aspecto, bem lembra Luigi Pareyson:

Não se pode enfrentar o problema do sentimento na arte sem distinguir, em primeiro lugar, várias espécies de sentimentos: aqueles vividos pelo artista antes da obra, aqueles expressos na obra, aqueles vividos pelo artista ao fazer a obra e aqueles despertados pela obra no leitor: em suma, os sentimentos precedentes, contidos, concomitantes e subsequentes com relação à obra de arte (PAREYSON, 1997, p. 84).

O artista se mistura com a essência da obra criada, sendo impossivel dissociar um do outro. No entanto, quando a música surge na literatura, é na forma de uma artificialidade imaginada pelo escritor de uma história de terror como um artificio para a criação de uma determinada atmosfera.

Refletindo por esse aspecto, ainda que existam inúmeros exemplos de músicas que tenham vindo ao mundo inspiradas pela atmosfera criada por uma narrativa de terror, é importante realçar que, quando servem como base para construção de uma história, não raro elas não existam na forma de som. Por estar dentro da obra literária é algo desprovido de ritmo ou de tonalidades, construindo-se somente sobre as impressões de um ouvinte - o narrador - que é quem a escuta e tenta transmitir o som para o leitor, usando somente palavras, fazendo o movimento que John Keats afirma na célebre poesia "Ode on a Grecian Urn", "heard melodies are sweet, but those unheard are sweeter" (KEATS, 2017).

Um exemplo disso acontece na história "A música de Erich Zann", escrita por H. P. Lovecraft. No conto, o narrador conhece um violeiro mudo, Erich Zann, que tocava uma música difícil de ser descrita:

\begin{abstract}
Fazendo um gesto para que me sentasse, o homem mudo fechou a porta, posicionou a trava robusta de madeira e acendeu uma vela para se somar àquela que trazia consigo. Em seguida removeu a viola da capa roída pelas traças e se sentou na menos desconfortável entre as cadeiras. Não usou a estante para partituras, mas, sem me permitir escolher e tocando de memória, me encantou durante uma hora inteira com melodias que eu nunca tinha ouvido antes; melodias que deviam ser de sua própria lavra. Descrever sua exata natureza é impossivel para alguém não versado em música. Eram uma espécie de fuga, com passagens recorrentes de uma qualidade das mais cativantes, porém para mim se fizeram notáveis mais pela ausência das notas estranhas que escutara do meu quarto em outras ocasiões (LOVECRAFT, 2018, p. 33).
\end{abstract}

A construção do cenário, onde o narrador e a personagem estão em um quarto sombrio, parcamente iluminado por uma vela, e a "capa roída pelas traças" traduz um ambiente pobre, decadente e ajuda a formar a atmosfera ideal para que a música apareça na narrativa de terror, mas sem nenhum som, só a descrição que se faz daquilo que está escutando. E, como é inevitável nos casos em que a música surge sem som dentro do texto literário, acaba sendo descrita por adjetivos, o que já foi inclusive analisado por Roland Barthes:

\begin{abstract}
Se examinarmos a prática corrente da crítica musical (ou conversações "sobre" música: é, frequentemente, a mesma coisa), veremos que a obra (ou sua execução) só é traduzida através da categoria linguistica mais pobre: o adjetivo. $O$ adjetivo é inevitável: esta música é isto, esta execução é aquilo. Evidentemente, do momento em que tomamos a arte como tema (de um artigo, de conversação), temos que atribuir-lhe um predicado; mas, no caso da música, este predicado toma fatalmente a forma mais fácil, mais trivial: o epiteto (BARTHES, 1990, p. 237).
\end{abstract}

Em outras referências à música tocada por Erich Zann, Lovecraft utiliza adjetivos para defini-la: "som inexprimivel", "música esquisita", "acordes inusitados", "música fantástica", "música selvagem" (LOVECRAFT, 2018). Ainda que o excesso de 
adjetivos seja algo que acaba tolhendo o texto literário - e sem chegar ao extremo sugerido por Roland Barthes, que desafia alguém a descrever um som sem usar adjetivos, mas outros predicados (BARTHES, 1990, p. 237-238) -, percebe-se que, em uma narrativa de terror como "A música de Erich Zann" de Lovecraft, os adjetivos acabam chamando atenção para o seu caráter terríico que sai da viola do velho mudo.

Eles fazem parte da atmosfera pretendida pelo autor, que utiliza os adjetivos de forma a contrastá-los com aquilo que o leitor inconscientemente espera de uma música. Não estão dispostos de forma desordenada - o que poderia mitigar o seu efeito, acabando por cansá-lo na tentativa de imaginar uma música -, mas se distribuem com parcimônia, fazendo com que cada pessoa imagine qual o tipo de música terrivel que sai do instrumento musical, preenchendo a falta de sons com a própria imaginação.

Analisando-se o conto, é possivel perceber que ela serve como um elemento de tensão justamente por causa da ausência de som. 0 único dado concreto da sua existência é fornecido por um narrador, que, como ocorre de praxe nas narrativas de terror, mistura os seus sentimentos, dúvidas e receios àquilo que está vivenciando.

Por outro lado, no conto "O jovem Goodman Brown", do escritor americano Nathaniel Hawthorne, a trilha surge na sua forma mais antiga, que é a música vocal. Os potenciais sonoros da voz humana e a sua capacidade de gerar sons sempre foram fonte de atração e estudos, sendo fato conhecido que, antes mesmo de se pensarem em instrumentos, ela era produzida na forma vocal. Importante recordar que boa parte das experiências religiosas mundiais está ligada à música vocal como forma de produzir estados de meditação e concentração (JOURDAIN, 1998, p. 131-132).

Da mesma forma que ocorre no conto de Lovecraft, somente o som não basta para constituir a atmosfera lúgubre em que se passa a história narrada por Hawthorne. Ao procurar a sua esposa Faith em meio a uma mata densa, todos os sons importam para Goodman Brown: "A floresta inteira estava povoada de sons assustadores - o estalar das árvores, o uivo de animais selvagens e o grito de índios; enquanto o vento às vezes soava como o dobrar do sino distante de uma igreja, e às vezes rugia em torno do viajante, como se toda a Natureza zombasse dele" (HAWTHORNE, 2016, p. 67). Esses sons que o circunda são essenciais para a construção da atmosfera fantasmagórica, em que a personagem caminha pela floresta em uma busca desesperada, até o momento em que eles irão se fundir à música vocal entoada por todos os moradores do povoado, envolvidos em um ritual secreto de invocação do Mal:

Deteve-se, numa calmaria da tempestade
que o impelira, e ouviu avolumar-se o que
parecia ser um hino, ressoando solenemente
a distância, engrossado por muitas vozes. Ele
conhecia a canção; era entoada muitas vezes
pelo coro no templo do povoado. Os versos ex-
tinguiram-se tristemente e foram prolongados
por um coro, não de vozes humanas, mas de
todos os sons da mata noturnal retumbando
juntos em horrivel harmonia. Goodman Brown
gritou, mas seu grito se perdeu no grito do
deserto e nem seu próprio ouvido o ouviu.
(HAWTHORNE, 2016, p. 67).

Chama atenção o pouco uso de adjetivos para construir o coral escutado pela personagem, assim como o progressivo aumento da tensão, que começa do silêncio da floresta, passa pelos sons típicos da natureza - notados pelo próprio Goodman Brown - e, em seguida, surge o eco frágil de um canto religioso já escutado no templo do povoado, o qual se junta aos ruidos noturnos para se transformar em um coro demoníaco. Utilizando a música vocal e o cenário como atmosferas para o surgimento do fantástico e do medo, Nathaniel Hawthorne consegue o efeito desejado no seu leitor, que passa a acreditar que Goodman Brown está prestes a sair do mundo real em que até então vivia para mergulhar em um outro cenário inóspito e cruel.

Assim como a personagem ingressa no clima soturno da narrativa, o mesmo acontece com quem está lendo a obra, que se vê aprisionado por uma música que não escuta e, por isso mesmo, é o mais assustador dos sons, uma vez que as próprias palavras humanas são insuficientes para descrevê-la com exatidão. Negar o som ao leitor é propiciar que a sua imaginação atue, adaptando 
a música para aquilo que cada um imagina ser o mais aterrorizante, como demonstra o momento culminante da música de acordo com Hawthorne:

Uma estrofe do hino elevou-se, uma toada lenta e plangente, como o amor piedoso, mas acompanhada de palavras que expressavam tudo o que nossa natureza pode conceber de pecaminoso e insinuavam enigmaticamente muito mais. A sabedoria dos demônios é insondável para meros mortais. Verso após verso foi cantado; e o coro dos ermos continuou a se avolumar entre um e outro como o tom mais grave de um órgão poderoso; com o ribombo final desse hino pavoroso, surgiu um som, como se do bramir do vento, do impeto das torrentes e do uivo das feras, e todas as outras vozes dos ermos dissonantes se misturaram e se harmonizaram com a voz do homem culpado em homenagem ao príncipe de todas as coisas. (HAWTHORNE, 2016, p. 69).

A música vocal deixa de ser exclusivamente humana e passa a ser entoada pelo mundo inteiro, configurando a necessária atmosfera para o desfecho do conto. Nesse sentido, assume a característica inicial das primeiras experiências sonoras da própria Humanidade, unindo o profano ao sagrado, o grotesco ao sublime. O efeito pretendido por Hawthorne na sua narrativa de terror - transportar quem lê para dentro de uma cerimônia pagã secretamente realizada em uma floresta da Nova Inglaterra, nos Estados Unidos - é conseguido, com o acréscimo de que o conto serve para abordar o protestantismo e o puritanismo, tão em voga na época, retratando os padres católicos como os responsáveis pela disseminação do mal.

Uma outra maneira que a música aparece em narrativas de terror vem a partir do excesso sonoro. Enquanto que em Lovecraft o som da viola de Erich Zann era tão singularmente assombroso que o personagem se sentia tanto fascinado quanto aterrorizado e, em Hawthorne, a música aparecia em um crescendo assumindo proporções colossais nas quais o mundo inteiro parecia estar cantando a mesma litania satânica, é possivel constatar um tipo de narrativas de terror em que a música aparece em excesso auditivo, deixando o leitor atordoado com a quantidade de referências musicais.

Um exemplo desse estilo é o conto "Sabe, eles têm uma orquestra do Diabo", de Stephen King (1997). Na história um casal em viagem acaba parando em uma cidade, Céu do Rock-and-Roll, em Oregon (EUA), onde estão as almas de todos os músicos que já passaram pela Terra, todos tocando de forma incessante, fazendo jams e experimentações, formando novos grupos e duplas, em uma balbúrdia infindável.

Stephen King não é um escritor que prima pela contenção. As suas narrativas de terror são vastas, repletas de frases, pensamentos e descrições que fingem uma desordenação sensorial (ainda que suas histórias sempre mantenham uma linha narrativa firme, ou seja, o efeito que pretende criar no leitor). Ele constrói a atmosfera pela superposição quase desenfreada de cenas e situações vivenciadas pelos personagens. O leitor se sente sufocar debaixo de tamanho manancial criativo, o que faz com que sua suspensão de descrença seja realizada quase à força, à medida que ele tenta penetrar no âmago da história, que o envolve como se fosse um polvo faminto.

Diante de tal estratégia criativa, o conto "Sabe, eles têm uma orquestra do Diabo" segue o estilo de King, sobrepondo músicos e sons de forma incessante, cada um deles tocando músicas próprias - que remetem ao conhecimento musical externo do leitor - e outras que são mencionadas no interior do texto - e que, por isso, precisam ser imaginadas. Por exemplo, quando a personagem Mary identifica a garçonete que the atende, pensa logo em uma música cantada por Janis Joplin, algo que pertence à sua memória e que, por existir no mundo real, pode ser acessada pelo leitor mais curioso:

Só que era mais do que um rosto e Mary sentiu o medo invadir seu peito, fazendo o coração de repente parecer leve, trôpego e em perigo.

Era a voz dela.

Com o ouvido da memória, ela ouviu o uivo ascendente, de dar calafrio, de Janis no início de Piece of my Heart. Ela colocou aquele berro de blues, meio embriagado, por cima da voz de uísque e Marlboros da ruiva, tal como tinha colocado um rosto sobre o outro, e se deu conta de que, se a ruiva começasse a cantar aquela música, sua voz seria idêntica à da falecida moça do Texas (KING, 1997, p. 292).

Com o intuito de construir a atmosfera desejada, Stephen King se detém na sensação de desconforto crescente da personagem Mary à 
medida que vai identificando os demais músicos mortos que se espalham pelo bar. Ao mesmo tempo, ela percebe que alguns frequentadores do bar estão amedrontados, como se fossem moscas presas na teia de uma aranha. Oscilando entre os pensamentos da personagem em estado bruto quase um fluxo de consciência - e a narrativa em primeira pessoa, o escritor americano faz o leitor experimentar o medo da personagem como se estivesse na sua pele, vendo a armadilha se fechar aos poucos e sendo impotente para escapar.

O clima de terror gradualmente se instaura na narrativa, guiado pela música, mas não por sons, e sim pelas referências espalhadas a respeito de outros cantores e cantoras já mortos e que. mesmo assim, frequentam a cidade. Ao mesmo tempo, nos devaneios guiados pelo receio do que possa lhes acontecer, a personagem imagina quais outros músicos podem estar em Céu do Rock-and-Roll, bem como toma conhecimento das funções que eles ocupam (por exemplo, Ottis Redding é o policial, Elvis Presley é o prefeito).

O conflito todo se define em torno de um grande e único espetáculo em que todos os músicos e bandas participam, espetáculo este em que o casal é obrigado a permanecer na plateia para assistir:

E não era nenhuma antiquada orquestra de sopro que ia tocar dentro de uns quinze a trinta minutos. Por todo o tablado (que aos olhos de Mary parecia tão grande quanto a Concha Acústica de Hollywood) estavam espalhados os implementos e acessórios do que tinha que ser a maior - e a mais barulhenta, a julgar pelos amplificadores - banda de rock androll do mundo, uma combinação apocaliptica do bebop que, no seu volume máximo, provavelmente teria força bastante para estilhaçar janelas de vidro a oito quilômetros de distância. Já tinha contado uma dúzia de guitarras em seus suportes quando parou de contar. Havia quatro conjuntos de baterias... bongôs... congas... uma seção de ritmo... pequenos palcos circulares elevados onde iriam ficar os cantores de fundo... um bosque metálico de microfones. (KING, 1997, p. 306)

Importante observar que, até esse momento, com exceção de algumas referências pontuais sobre as canções que os músicos tocaram no passado, quase não são feitos comentários sobre o que eles tocam agora que estão reunidos no pós-morte. Do ponto de vista de Mary, personagem e narradora, é uma música que não foi feita para ouvidos humanos, e o próprio leitor se interroga sobre como ela será. A julgar pelas menções feitas por outras personagens igualmente aprisionadas naquela cidade, era melhor evitar ouvi-la a qualquer custo, o que justifica o crescimento de uma atmosfera sufocante à medida que o espetáculo se arma e fracassam as tentativas de fuga.

Ao contrário do esperado, o efeito que Stephen King deseja criar no leitor não é a identificação com a dupla de personagens que, de forma involuntária, entrou em uma cidade da qual não conseguem fugir, mas imaginar o que será executado pela maior orquestra de músicos que já tocaram em todos os tempos. Pelo fato do conto não contar com um artefato que permita a reprodução física da música - e até por que, mesmo se existisse uma forma de transformar essa música imaginária em algo real, ela dificilmente seria tão aterradora e grandiosa quanto existe na imaginação do leitor -, tal satisfação da curiosidade é constantemente negada.

Além disso, por meio das dúvidas da narradora sobre a sua natureza, o leitor não sabe se ela será tão hedionda que o conduzirá à loucura ou tão celestial que o enlevo lhe levará ao entorpecimento, a um gozo tão supremo que se confunde com a morte. Por este motivo, o conto converge de maneira suave para o parágrafo final, momento em que os músicos sobem ao palco e finalmente começa o show tão temido:

\begin{abstract}
Enquanto as luzes do show se acendiam e a orquestra entrou na primeira canção do concerto comprido, comprido, daquela noite - Vou P'ros Infernos, com Marvin Gaye fazendo o vocal -, Mary pensou: É disso que eu tinha medo. É exatamente disso que eu tinha medo. (KING. 1997, p. 310) (grifos no original)
\end{abstract}

Existe todo um cuidado de King em não descrever a música, deixando o leitor encarregado de imaginá-la. A circunstância do conto terminar em aberto - afinal, exatamente do que Mary tinha medo? - conduz a outro elemento essencial em uma narrativa de terror: a negação da satisfação.

O leitor não terá satisfeito o seu desejo por respostas; precisará arcar com a frustração de não ter saciada a própria curiosidade. Nem sempre 
funciona: às vezes, a insatisfação pela ausência de explicações é tão devastadora que faz o público se decepcionar com a leitura como um todo.

Em outras ocasiões, o leitor se envolve em uma série de discussões e debates com outros tentando chegar ao entendimento completo da narrativa, com ambos os lados elencando fatos e justificativas que estão na narrativa. No entanto, pela construção da história de Stephen King, podemos compará-la a uma casa com múltiplas portas e janelas, em que o escritor deixa entreabertas várias possibilidades de contemplar as respostas que estão na rua, e cada leitor pode optar por seu caminho de interpretação, ou seja, qual porta ou janela irá escolher como saída.

\section{Considerações Finais}

O mistério da música sem som tocada dentro de uma narrativa permanece intacto. Nos três contos aqui abordados, é possivel notar que foi colocada na trama de diferentes maneiras, mas sempre como catalisador da tensão e da atmosfera narrativa.

Ela não é um elemento passivo acrescentado no conto como ambientação, mas dialoga com a trama e permite o acesso a outras camadas de entendimento, construindo o terror por meio do universo de significados que se escondem dentro de ondas sonoras. Ainda que o leitor não consiga escutar a viola de Erich Zann, o coral de vozes dentro de uma floresta em New England ou a canção tocada em Céu do Rock-and-Roll, preenche esse silêncio com a sua ideia de música, o que a aproxima de uma característica da linguagem, conforme afirma Barthes:

O que vem a ser a música? A arte de Panzéra pode responder: é uma qualidade da linguagem. Qualidade que em nada depende das ciências da linguagem (poética, retórica, semiológica), pois, ao tornar-se qualidade, o que é promovido, na linguagem, é aquilo que não é dito, não é articulado pela linguagem. No não-dito, vêm-se instalar o gozo, a ternura, a delicadeza, o contentamento, todos os valores do mais delicado Imaginário. A música é, ao mesmo tempo, o expresso e o implicito do texto: é o que é pronunciado (submetido a inflexões), mas não é articulado: é aquilo que está simultaneamente fora do sentido e do sem-sentido,inteiro nessa significância que, hoje, a teoria do texto tenta postular e situar (BARTHES, 1990, p. 252).
Ao considerarmos a música como uma qualidade da linguagem, chama atenção que o Brasil, mesmo sendo considerado um país extremamente musical, conhecido no mundo todo pela sua inventividade no que diz respeito a ritmos e sonoridades, não a utiliza muito como elemento constitutivo da trama, ainda mais quando consideramos o gênero do terror. A literatura brasileira de terror ainda se prende em demasiado ao sentido da visão, deixando de lado as ricas possibilidades que se escondem quando pensamos o som - de acordo com as palavras de Barthes (1990, p. 252) - "como uma bela metáfora".

Para efeitos dos estudos no campo da Escrita Criativa, é importante observar que uma história de terror eficiente é construida por intermédio de estratégias narrativas que formam a atmosfera ideal para produzir o efeito desejado pelo autor. Neste contexto, a música pode funcionar como uma maneira de elevar a tensão da trama, brincando com o leitor no momento em que sugere sons que não saem do livro, mas só existem na sua imaginação.

Sem perceber, o leitor acaba fazendo a trilha sonora da própria narrativa, um som que não existe na sua forma física, audivel, mas que é parte essencial do medo transmitido pela história. Estudar a música na sua forma literária é uma das maneiras de abrir o leque de estudos sobre os textos ficcionais brasileiros, assim como permite uma investigação mais criteriosa da importância do efeito e da atmosfera em uma narrativa.

\section{REFERÊNCIAS}

ALVES, Claudia; MATOS, Gabriela. Na trilha do medo. ECLÉTICA, n. 30, p. 17-20, 2010. Disponivel em: http:// puc-riodigital.com.puc-rio.br/media/4_-_a_trilha_do_ medo.pdf Acesso em: 14 set. 2019.

ARISTÓTELES. Política. 6. ed. Tradução de Pedro ConstantinTolens. São Paulo: Martin Claret, 2006

BARTHES, Roland. O óbvio e o obtusoi ensaios criticos III. Tradução de Léa Novaes. Rio de Janeiro: Nova Fronteira, 1990.

BORGES, Jorge Luis. Esse ofício do verso. Tradução de José Marcos Macedo. São Paulo: Companhia das Letras, 2010.

BURROWS, John (org.). Guia de música clássica. 4. ed Tradução de André Telles. Rio de Janeiro: Jorge Zahar Ed., 2010. 
CARPEAUX, Otto Maria. O livro de ouro da História da Música, da ldade Média ao século XX. 7. ed. Rio de Janeiro: Ediouro, 2005.

CARREIRO, Rodrigo. Sobre o som no cinema de horror: padrões recorrentes de estilo. Ciberlegenda, v. 1, n. 24. p. 43-53, 2011. Disponivel em: http://www.ciberlegenda. uff.br/index.php/revista/article/view/381/254 Acesso em: 13 set. 2019. https://doi.org/10.22409/c-legenda. v1i24.26201.

CASTELLO, José. Ribamar. Rio de Janeiro: Bertrand Brasil, 2013

CASTRO, Gustavo. O Compêndio de música de René Descartes - entendimento e anotações sobre a tradução. Dissertação (Mestrado) - Programa de Pós-Graduação em Filosofia, UFPB, 2005. Disponivel em: https://repositorio.ufpb.br/jspui/handle/tede/8327. Acesso em: 14 set. 2019.

CIENTISTAS descobrem por que as trilhas sonoras de filmes de terror assustam. VEJA [online], 26 maio 2010. Disponivel em: https://veja.abril.com.br/entretenimento/ cientistas-descobrem-por-que-as-trilhas-sonoras-dos-filmes-de-terror-assustam/ Acesso em: 13 set. 2019.

COMPAGNON, Antoine. O demônio da teoria: literatura e senso comum. Tradução de Cleonice Paes Barreto Mourão e Consuelo Fortes Santiago. Belo Horizonte: UFMG, 1999.

CURRIE, Gregory. The nature of fiction. New York: Cambridge University Press, 1993.

CZEKSTER, Gustavo Melo. O tempo, a música e a narrativa. (Des)limiares da linguagem. In: COLÓQUIO DE LINGUISTICA, LITERATURA E ESCRITA CRIATIVA. PROGRAMA DE PÓS-GRADUAÇÃO EM LETRAS DA PUC-RS, 9., 2016, Porto Alegre. Anais [...]. Porto Alegre: PUCRS, 2016. p. 299-310

HAWTHORNE, Nathaniel. O jovem Goodman Brown. In: COSTA, Flávio Moreira da. Os melhores contos fantásticos. 2. ed. Tradução de Maria Luiza X. de A. Borges. Rio de Janeiro: Nova Fronteira, 2016. p. 57-72.

JOURDAIN, Robert. Música, cérebro e êxtase: como a música captura nossa imaginação. Tradução de Sonia Coutinho. Rio de Janeiro: Objetiva, 1998.

KEATS, John. Ode on a Grecian Urn. Chicago: Poetry Foundation, 2017. Disponivel em: https://www.poetryfoundation.org/poems/44477/ode-on-a-grecian-urn Acesso em: 12 set. 2019.

KING, Stephen. Pesadelos e paisagens noturnas. Vol. I. Tradução de M. H. C. Cortês. Rio de Janeiro: Objetiva, 1997.

KING, Stephen. Sobre a escrita: a arte em memórias. Tradução de Michel Teixeira. Rio de Janeiro: Objetiva, 2015.

KOTHE, Flávio R. Literatura e sistemas intersemióticos. São Paulo: Cortez Autores Associados, 1981.

LOVECRAFT, H. P. O chamado de Cthulhu e outros contos. Tradução de Alexandre Boide. Porto Alegre: L\&PM, 2018.

LOVECRAFT, H. P. O horror sobrenatural em literatura. Tradução de Celso M. Paciornik. São Paulo: lluminuras, 2007.
MLA style: The Nobel Prize in Literature 2016 -- Press Release. Nobelprize.org, [s. l.], Nobel Media AB 2014. 2016. Disponivel em: http://www.nobelprize.org/ nobel_prizes/literature/laureates/2016/press.html. Acesso em: 12 set. 2019

PAREYSON, Luigi. Os problemas da estética. 3. ed Tradução de Maria Helena Nery Garcez. São Paulo: Martins Fontes, 1997.

POE, Edgar Allan. Poemas e ensaios. 3. ed. Tradução de Oscar Mendes e Milton Amado. São Paulo: Globo, 1999.

POUND, Ezra. A arte da poesia: ensaios escolhidos. Tradução de Heloysa de Lima Dantas e José Paulo Paes. São Paulo: Cultrix, 1976.

RHODES, James. Instrumental: memórias de música, medicação e loucura. Tradução de Luís Reyes Gil. Rio de Janeiro: Rádio Londres, 2017.

SANCHES NETO, Miguel. Contos para ler ouvindo música. Rio de Janeiro: Record, 2005.

SCHER, Steven Paul. Literature and music. In: BERNHART, Walter; WOLF, Werner. Word and music studies. Essays on literature and music (1967-2004) by Steven Paul Scher. Nova York: Rodopi, 2004. p. 173-202.

TAVARES, Sérgio (org.). Cobain: 25 contos inspirados em 25 anos do álbum Nevermind + bônus tracks. [S. l.: s. n.]: 2016. Disponivel em: https://issuu.com/coletaneacobain/docs/cobain. Acesso em: 14 set. 2019.

WAGNER, Richard. Beethoven. Tradução de Anna Hartmann Cavalcanti. Rio de Janeiro: Zahar, 2010.

\section{Gustavo Melo Czekster}

Possui graduação em Ciências Jurídicas e Sociais pela Pontifícia Universidade Católica do Rio Grande do Sul (PUCRS), especialização em Pós-Graduação em Assessoria Linguistica e Textual pelo Centro Universitário Ritter dos Reis (UniRitter) e mestrado em Letras pela Universidade Federal do Rio Grande do Sul (UFRGS). 